\title{
Evaluasi Discrepancy Program Parenting Class dalam Rangka Meningkatkan Hubungan Masyarakat
}

\author{
Esther Yuli Ekawati ${ }^{{ }_{1}}$, Ade Iriani ${ }^{2}$ \\ Manajemen Pendidikan, Universitas Kristen Satya Wacana \\ DOI: $\underline{10.31004 / o b s e s i . v 5 i 1.525}$
}

\begin{abstract}
Abstrak
Penelitian ini bertujuan untuk memberi evaluasi pada program parenting pada KB-TK Bethany School Salatiga. Penelitian ini merupakan penelitian evaluatif kualitatif menggunakan model Discrepancy Evaluation Method oleh Provus (1971) melalui 5 tahapan desain, instalasi, proses, produk, analisis biaya manfaat. Data dikumpulkan dengan menggunakan wawancara kepala sekolah, empat guru dan tiga orang tua, observasi dan dokumentasi. Analisis data menggunakan pengumpulan data, reduksi data, penyajian data dan verifikasi. Berdasarkan penelitian, tujuan program tercapai. Hasil penelitian menemukan bahwa program parenting di KB-TK Bethany School Salatiga dinilai baik dengan deskripsi tahap desain, tahap instalasi, tahap di sekolah memenuhi delapan puluh persen aspek milik pemerintah, tahap empat tujuan tercapai sehingga bernilai baik. Dalam tahap perbandingan dengan program lain, masing-masing program bermanfaat tetapi saling mendukung. Ditemukan empat kesenjangan dalam program yaitu belum terlaksananya keterlibatan orang tua di dalam kelas, terhentinya kegiatan parents to parents Belum adanya gabungan berita dan bacaan pendamping, pengasuh ikut dalam program. Peneliti menyarankan untuk melanjutkan program ini dengan perbaikan.
\end{abstract}

Kata Kunci: evaluasi program; discrepancy; parenting class.

\begin{abstract}
This study intends to evaluate parenting class program of KB-TK Bethany School, Salatiga. This is an evaluative quantitative research using discrepancy evaluation model by Provus (1971) through 5 steps of evaluation (design, installation, process, product, cost-benefit analysis). Data were collected by using interviews with principal, four teachers, three parents, observation and documentation. Data analysis includes data collection, data reduction, data display and verification. Based on the research and findings, the program has a good assessment with these details: first until fitfth steps has more than eighty percents aspects compared to the government aspects there are four discrepancies found in the program; Parents are not involved in classroom learning, Parents to parents activity is discontinuing, no news collection and reading for parents, Participants are not only from family but also baby sitter. Researcher suggest that school continue doing this program by adding more improvements.
\end{abstract}

Keywords: program evaluation; discrepancy; parenting class.

Copyright (c) 2020 Esther Yuli Ekawati,, Ade Iriani

$\triangle$ Corresponding author:

Email Address : pixie.esther@gmail.com (Salatiga, Jawa Tengah, Indonesia)

Received 29 April 2020, Accepted 8 May 2020, Published 12 May 2020 


\section{PENDAHULUAN}

Sekolah merupakan lembaga formal yang menyelenggarakan pendidikan bagi peserta didik tidak dapat dilepaskan dari dari salah satu bagian yang mendukungnya yaitu masyarakat sekolah. Untuk dapat menarik perhatian masyarakat, sekolah berusaha meningkatkan mutu dan pelayanan. Pemerintah dalam Permendiknas no 19 tahun 2007 menyebutkan bahwa lembaga pendidikan melibatkan warga masyarakat dalam mengelola pendidikan. Ditambahkan oleh (Pidarta, 2011) bahwa sekolah yang dapat membina hubungan baik dengan masyarakat, akan dapat bertahan lama meskipun pada awalnya sekolah belum memiliki fasilitas yang beragam. Menurut (Cutlip et al., 2011), untuk menilai sikap masyarakat, melihat kembali kebijakan dan cara seseorang atau organisasi untuk kepentingan masyarakat, merencanakan serta melakukan program, sehingga akan didapat pengertian, pemahaman dan dukungan umum adalah salah satu fungsi dalam manajemen hubungan masyarakat.

Dalam pembahasan mengenai lembaga pendidikan yang harus mengakomodasi tuntutan masyarakat, terdapat stakeholder yang merupakan masyarakat sekolah di dalam sekolah itu sendiri maupun di lingkungan sekitar sekolah. Stakeholder tersebut mempunyai hubungan, baik secara langsung atau tidak, terhadap manajemen sekolah, sadar secara sosial serta berpengaruh ke sekolah. Pengelompokan stakeholder dibagi menjadi dua bagian diantaranya internal dan eksternal. Yang tergolong dalam stakeholder internal adalah mereka yang ada di dalam lingkungan sekolah seperti kepala sekolah, pengajar, peserta didik, staff tata usaha. Yang termasuk dalam stakeholder eksternal ialah masyarakat di sekitar lingkungan sekolah yang mendukung sekolah seperti komite sekolah, orang tua peserta didik, serta pengawas sekolah(Ulva, 2017)

Salah satu stakeholder sekolah adalah orang tua murid. Pada era ini, banyak orang tua yang ingin agar anak dapat mengenyam pendidikan pada usia dini. Hal tersebut dikarenakan orang tua murid punya tujuan bahwa dengan memasukkan anak ke salah satu lembaga pendidikan, perkembangan kognitif, motorik dan sosial anak dapat berkembang dengan maksimal.

Namun, keinginan besar orang tua tersebut kurang diimbangi dengan kemampuan mereka untuk memahami program dan tujuan sekolah dalam rangka melaksakan pendidikan anak. Kasus guru dengan orang tua murid marak terjadi akibat, komunikasi antara sekolah dan orang tua tidak bekerja dengan baik, demikian menurut Pengamat Kebijakan Publik UGM, Dr.soc.pol. Agus Heruanto Hadna (2016). Disisi lain, banyak orang tua yang kurang peduli apa yang terjadi dengan anak dan dipelajari anak di sekolah. Mereka merasa sudah membayar mahal biaya sekolah, sehingga mereka merasa tidak perlu lagi mendidik anak di rumah. Padahal keluarga adalah organisasi yang sangat penting dalam penciptaan pendidikan dan perkembangan awal seorang anak (Nelliraharti Nelliraharti \& Sari, 2019). Keluarga juga merupakan unit paling kecil di masyarakat, tempat pertama dimana anak memperoleh pendidikan, sehingga fungsi keluarga dalam pendidikan dan bidang sosial anak harus dijalankan secara selaras oleh sekolah dan keluarga (Siti Chumaerotin et al., 2019)

Mencermati keadaan tersebut, dapat dilihat bahwa ada kesenjangan yang terjadi di pihak sekolah dan orang tua murid, yang akan menimbulkan kebingungan pihak sekolah. Orang tua dan sekolah tidak dapat bekerja sama dengan maksimal, karena proses pendidikan tidak sejalan. Akibatnya proses belajar mengajarpun akan terganggu, yang dampak akhirnya adalah tujuan awal menyekolahkan anak agar dapat berkembang akan gagal.

Diperlukan kerjasama yang baik antara sekolah dan orang tua peserta didik sehingga hasil pendidikan anak dan keinginan sekolah dapat tercapai dengan baik (Permatasari et al., 2019). Oleh karena itu, kerja sama antara orang tua dan sekolah wajib di galakkan untuk mengatasi kesenjangan antara pihak sekolah dengan guru tersebut. Perlu adanya keterlibatan orang tua dalam lingkup sekolah, yaitu sebagai partner kerja atau sebagai 
pengajar di rumah, dengan menyediakan program parenting agar orang tua dapat melakukan tugasnya sebagai pengajar tersebut (Lindasari et al., 2017)

Sekolah dapat membuat membuat sebuah program dimana guru dan orang tua dapat bertemu untuk menyatukan tujuan pendidikan anak, yang diadakan di sekolah. Program tersebut dapat membawa partisipasi orang tua dalam ikut serta mendukung pelaksanaan pendidikan anak (Ayudia, 2014). Program merupakan sebuah rencana yang akan dilakukan. Menurut (Arikunto \& Safrudin Abdul Jabar, 2009) ada tiga hal penting yang perlu ditekankan dalam menentukan program, yaitu (1) wujud kebijakan (2) terjadi dalam kurun waktu lama dan bekesinambungan dan (3) terjadi di organisasi yang didalamnya ada sekumpulan orang.

Program tersebut dapat berupa program parenting. (Sudjana, 2017) menyampaikan bahwa untuk bisa meningkatkan kemampuan, memperluas wawasan, menambah dan keahlian, get memperoleh trik baru, dan memperbaiki tindakan orang yang sudah dewasa merupakan tujuan dari program parenting. Ditambahkan oleh (Lenny Nuraeni, Andrisyah, 2019) yang mengutip Jazariyah, parenting ada pada tempat penting untuk membentuk karakter seorang anak.

(Fitroh \& Oktavianingsih, 2020) menyatakan bahwa program pendidikan parenting bermanfaat dalam penemuan penyelesaian masalah melalui komunikasi yang interaktif mengenai tumbuh kembang anak dan pemenuhan hak anak.

Menurut (Rahayu, 2018) Contoh program parenting yang dapat dilakukan di lembaga pendidikan anak usia dini yaitu pertemuan orang tua dan pengelola PAUD dan guru (1), melibatkan orang tua di dalam kelas untuk belajar bersama (2), melibatkan orang tua dalam acara bersama (3), menjadwalkan hari musyawarah antara orang tua, pengelola dan pendidik untuk membahas tumbuh kembang anak (4), kunjungan pengelola dan guru ke rumah peserta didik (5), hal tersebut sesuai dengan Pedoman Penyelenggaraan PAUD berbasis Keluarga (Direktorat Pembinaan Pendidikan Anak Usia Dini Direktorat Jenderal Pendidikan Anak Usia Dini, 2012).

Penelitian yang relevan mengenai program parenting dilakukan oleh (Nooraeni, 2017) mengenai implementasi program parenting yang salah satu hasilnya adalah bahwa faktor penghambat pelaksanaan yaitu kesulitan ekonomi, adaptasi dan banyak orang tua tidak dapat menghadiri maupun terlambat. Penelitian selanjutnya dilakukan oleh (S., 2018) mengenai pengaruh program parenting terhadap perkembangan kemandirian anak usia dini, dengan hasil bahwa program parenting membawa dampak positif terhadap perkembangan kemandirian anak, dengan orang tua yang ikut berpartisipasi dalam sinkronisasi program sekolah.

Kelompok Bermain (KB) -Taman Kanak-kanak (TK) Anak Terang (Bethany School) Salatiga merupakan salah satu sekolah anak usia dini yang telah melaksanakan berbagai program dan memiliki berbagai fasilitas untuk dapat bersaing dengan sekolah lain. Bethany School Salatiga melihat bahwa hubungan masyarakat selayaknya berjalan dengan baik, terutama dengan orang tua peserta didik. Hal ini sejalan dengan penelitian yang menyatakan bahwa pengelolaan hubungan masyarakat yang baik dapat berdampak positif dalam usaha untuk mencapai tujuan sekolah (Siregar, 2018). Salah satu misi Bethany School Salatiga adalah menjadikan orang tua sebagai partner sekolah dalam rangka mendidik para siswanya. Sekolah ingin agar orang tua ikut andil dalam mendidik putra - putri mereka. Program yang telah dibuat salah satunya adalah Parenting class yang merupakan pertemuan antara orang tua dan guru setiap satu bulan sekali. Orang tua akan datang ke sekolah setiap satu bulan sekali, bertemu dengan wali kelas anak masing-masing untuk membicarakan kegiatan yang akan dilakukan anak selama satu bulan yang akan datang. Hal tersebut merupakan bentuk nyata dari strategi sekolah yaitu "Parents as a Partner". Bethany School Salatiga hendak menjadikan orang tua sebagai kawan dan mengajak orang tua untuk bersama-sama mendidik anak, sehingga kualitas manusia yang berkarakter baik akan didapatkan. 
Oleh karena itu peneliti tertarik untuk melakukan evaluasi terhadap program parenting class di KB-TK Bethany School. (Arikunto \& Safrudin Abdul Jabar, 2014) yang mengutip Tyler (1950) menyatakan bahwa proses untuk mengetahui apakah tujuan sudah tercapai disebut dengan evaluasi program. Hasil dari evaluasi program yang dilakukan akan bermanfaat bagi pelaksanaan program selanjutnya. (Putri, 2019)

Penelitian ini menggunakan model evaluasi discrepancy yang dikembangkan oleh Provus (1971). Model penelitian ini tidak membuktikan sebab dan akibat, akan tetapi lebih melihat apakah yang diharapkan sesuai dengan yang terjadi (Yusup et al., 2019). Model ini juga berfokus pada visi tentang adanya kesenjangan di dalam implementasi program. Kesenjangan yang dimaksud yaitu apa yang diharapkan pada rencana atau standar program dengan hasil dalam aplikasi program. Standar merupakan kriteria yang ditentukan dengan harapan ada hasil yang efektif. Seperti yang dikemukakan oleh Yavorsky (1984) dalam (Rahman et al., 2018), standar juga bisa disebut desain program. Kesenjangan juga muncul jika hasil lebih tinggi atau kebih rendah dari standar.

Evaluasi menurut Provus dijabarkan sebagai proses dari (1) memutuskan standar program; (2) memutuskan perbedaan antara kinerja dan standar; (3) memanfaatkan ketidakserasian sebagai sarana mengubah kinerja atau standar (Ftizpatrick et al., 2004)

(Rahman et al., 2018) menyatakan ada 5 tahap untuk mengevaluasi dengan menggunakan DEM (Discrepancy Evaluation Model), yaitu: desain program, yaitu informasi mengenai rancangan program/desain (1), instalasi, yaitu perbandingan program dengan instalasi (2), proses pelaksanaan, untuk menilai apakah proses dapat mengubah input menjadi output (3), hasil program, evaluasi diadakan untuk melihat apakah tujuan program telah dicapai dengan mengevaluasi hasil program (4), analisis biaya manfaat, digunakan untuk membandingkan program yang diteliti dengan program lain yang kurang lebih sama, untuk menentukan program manakah yang lebih baik untuk dilakukan agar alokasi menjadi efektif. (5), seperti yang dikemukakan oleh Provus (1971) dan Yavorsky (1984).

Berdasarkan masalah diatas, penelitian ini akan mengevaluasi proses pelaksanaan program parenting class, hasil pelaksanaan program parenting class di KB-TK Bethany School Salatiga tahap 1 sampai 5, dan kesenjangan program parenting class, agar KB-TK Bethany School dapat memutuskan untuk melanjutkan program, menghentikan atau melanjutkan dengan perbaikan.

\section{METODOLOGI}

Metode penelitian yang digunakan yaitu penelitian kualitatif evaluatif dengan model discrepancy. Penelitian dilaksanakan di KB-TK Bethany School Salatiga dengan alamat Jalan Jendral Sudirman No 61. Salatiga. Sumber informasi meliputi: Kepala Sekolah, empat Guru KB dan TK A dan B, dan tiga orang tua siswa. Sumber-sumber data yang digunakan di penelitian diantaranya hasil program parenting class, jadwal proses kegiatan, dan rencana. Wawancara secara tatap muka, observasi dan studi dokumentasi merupakan teknik koleksi data untuk penelitian evaluasi program parenting class di KB-TK Bethany School Salatiga. Beberapa langkah dalam analisis data dalam penelitian ini yaitu: (1) Penghimpunan data, (2) Penguranan data, (3) Penyajian data, (4) Kesimpulan data. Uji validitas data menggunakan teknik triangulasi sumber dan triangulasi teknik. 


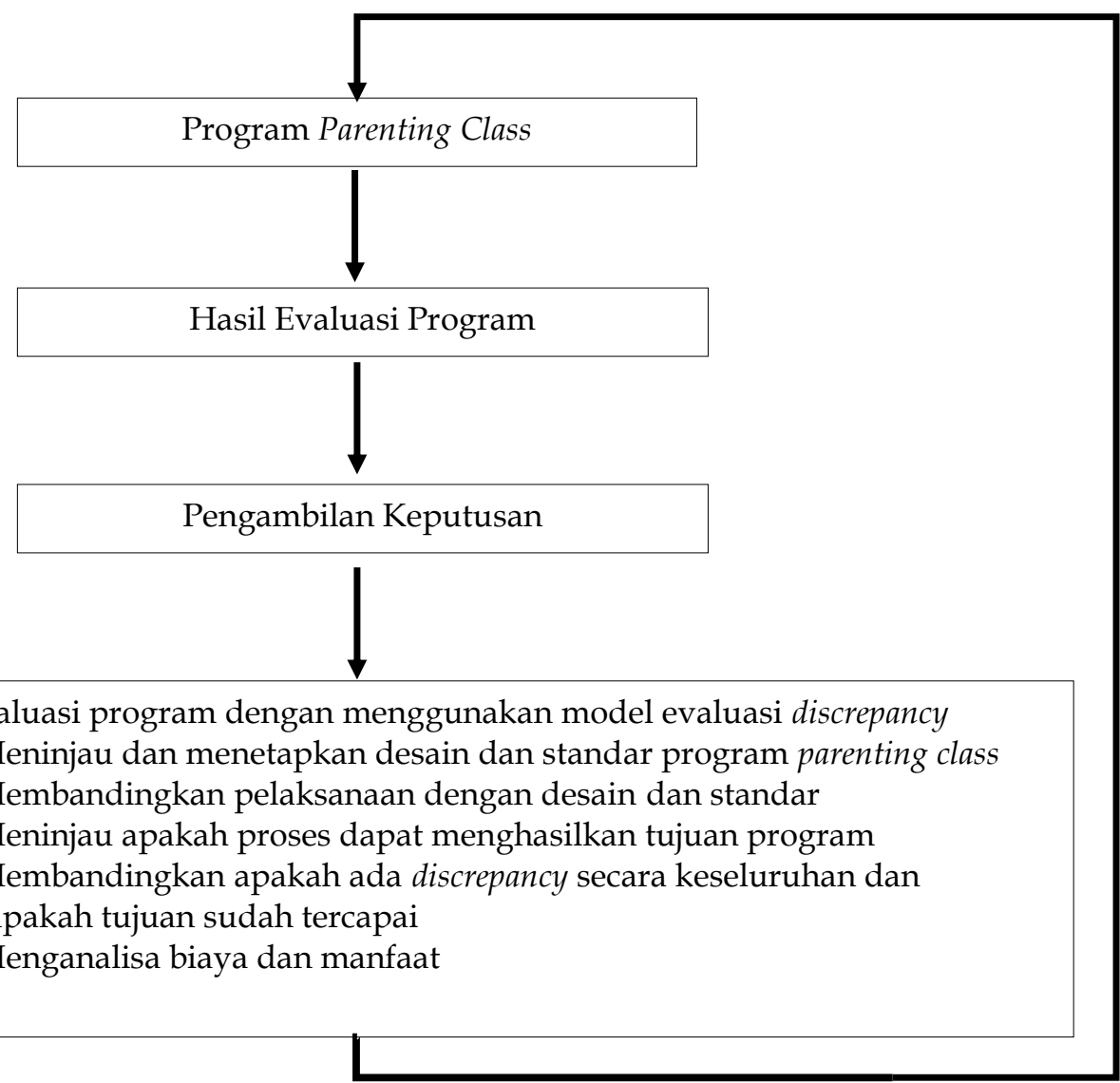

Gambar 1 Desain penelitian

\section{HASIL DAN PEMBAHASAN}

\section{Evaluasi tahap 1 penelitian discrepancy program parenting class di KB-TK Bethany School Salatiga.}

Pada tahap 1, yaitu desain program, peneliti menganalisis tentang rancangan program parenting class yang didalamnya berisi tujuan, peserta program, dan dasar pelaksanaan program. Berdasarkan hasil wawancara yang telah dilakukan dengan kepala sekolah, latar belakang pelaksanaan program parenting class adalah sebagai bentuk nyata strategi sekolah yaitu Strategi yang dimiliki sekolah tersebut, dalam rangka mendukung visi dan misi sekolah yaitu "Parents as a Partner", dimana sekolah mempunyai keinginan untuk menjadikan orang tua sebagai rekan bagi pengajar. Sekolah berharap bahwa setiap orang tua murid tidak hanya menjadi penonton dan cukup mengetahui apa yang menjadi program sekolah dan yang diajarkan di sekolah. Lebih dari itu, sekolah ingin agar setiap orang tua murid dapat menjadi rekan yang bersama-sama dengan guru, mendidik murid dan mendukung setiap program sekolah dengan baik.

Dengan strategi tersebut, sekolah menciptakan sebuah program yang disebut dengan parenting class, agar dapat mewadahi orang tua siswa, agar dapat mengikuti materi di sekolah, serta menyamakan cara pengajaran di sekolah dan di rumah. Maka peserta dari parenting class adalah orang tua siswa. Kepala Sekolah menyampaikan bahwa latar belakang disusunnya program parenting class ini adalah karena kepedulian sekolah terhadap memajukan pendidikan anak usia dini terutama di Salatiga dengan menggunakan Bahasa Inggris sebagai pengantar. Untuk mempermudah pembelajaran sekolah menetapkan sebuah teknik yaitu dengan mengajarkan bunyi huruf dan bukan alphabet. Hasil dari pelaksanaan program tersebut adalah orang tua diharapkan memahami materi pembelajaran untuk bulan depan, sehingga dapat mempersiapkan segala keperluan anak dan juga membantu anak belajar di rumah. 


\section{Evaluasi tahap 2 penelitian discrepancy program parenting class di KB-TK Bethany School} Salatiga.

Pada tahap 2, yaitu instalasi program, peneliti akan menganalisis tentang instalasi program parenting class. Instalasi dalam program parenting class di KB-TK Bethany School yaitu Kepala Sekolah yang merupakan penanggung jawab program, guru kelas sebagai penyelenggara program, salah satu guru sebagai koordinator / perwakilan sekolah dalam komite orang tua, administrasi sekolah sebagai petugas filing dokumen pelaksanaan program parenting class, dan orang tua siswa sebagai peserta sekaligus warga masyarakat sekolah yang mengikuti program parenting class. Guru yang masuk dalam tiap pertemuan di jenjang toddler, nursery dan preschool adalah semua guru pengampu di jenjang tersebut. Guru yang akan masuk di pertemuan di jejang TK akan dibagi bergiliran masing-masing 2 guru di tiap bulannya. Hal tersebut dilakukan agar proses belajar mengajar tetap berlangsung.

Sarana dan prasarana yang digunakan dalam pelaksaaan program parenting class yaitu ruang kelas, ruang pertemuan, jadwal masing-masing kelas yang telah di upload ke website dan aplikasi sekolah, LCD, laptop, microphone. Sesuai wawancara dengan empat guru dan tiga orang tua siswa, sarana dan prasarana yang digunakan dalam pelaksanaan sudah cukup. Tiga orang tua siswa mengatakan bahwa mereka senang dan dengan sarana dan prasarana yang digunakan dalam penyelenggaran program parenting class.

Para guru juga menyampaikan bahwa selama ini apa yang dilakukan sudah maksimal. Hal ini di perkuat dengan pernyataan Kepala Sekolah yang menyampaikan bahwa ruang kelas dan ruang pertemuan sudah digunakan secara maksimal. Ruang kelas dan ruang pertemuan tersebut dilengkapi dengan pendingin ruangan yang cukup membuat orang tua siswa yang hadir merasa nyaman, sehingga proses penyampaian materi dapat berjalan dengan lancar. Dengan sarana dan prasarana tersebut, orang tua siswa dapat mendengar penjelasan guru dengan baik, sehingga persiapan pembelajaran di bulan selanjutnya dapat berjalan dengan baik.

Dengan cukupnya sarana prasarana yang ada, ternyata belum membuat orang tua siswa merasa puas. Beberapa dari orang tua berharap bahwa sekolah dapat menyediakan tambahan sarana berupa pena untuk menulis hal-hal penting, dikarenakan tidak semua orang tua merasa puas dengan mencatat menggunakan gadget.

Akan tetapi, peserta program parenting class, yang seharusnya dihadiri oleh seluruh orang tua siswa, pada kenyataanya tidak semua orang tua dapat menghadiri parenting class. Sebagian orang tua siswa adalah orang tua yang bekerja dan tidak memungkinkan untuk menghadiri parenting class yang diadakan pada jam kerja tersebut. Oleh karena itu, para orang tua mengirim perwakilan, dalam hal ini perwakilan adalah nenek/kakek dari siswa dan pengasuh anak siswa. Dengan dikirimnya perwakilan tersebut, para orang tua berharap agar info dari sekolah dapat diteruskan kepada mereka.

Berdasarkan wawancara dengan empat guru, hasil tersebut tidak sinkron dengan apa yang sudah direncanakan dalam program. Hasil yang diharapkan dari program adalah orang tua mengetahui rancangan pembelajaran untuk bulan ke depan. Akan tetapi beberapa dari perwakilan orang tua tersebut tidak dapat menyampaikan hasil program secara maksimal, sehingga beberapa informasi dari guru dan sekolah terlewatkan oleh orang tua siswa. Dengan mempertimbangkan hal tersebut, orang tua juga menyarankan agar sekolah dapat memfasilitasi dengan menyampaikan hasil dari pelaksanaan program parenting class melalui group Whatsapp di masing-masing kelas. Orang tua sangat berharap agar mereka tidak melewatkan satu informasipun dari hasil parenting class.

\section{Evaluasi tahap 3 penelitian discrepancy program parenting class di KB-TK Bethany School Salatiga.}

Pada tahap 3, yaitu instalasi program, peneliti akan menganalisis tentang proses pelaksanaan program parenting class. Program parenting class ini dilaksanakan secara rutin setiap bulan. Proses persiapan yang dilakukan yaitu dengan cara (1) memberikan pengumuman kepada orang tua siswa bahwa akan diadakan parenting class. Pengumuman 
tersebut kemudian akan ditempel di buku komunikasi orang tua dan guru, di upload melalui media sosial resmi sekolah (Instagram, Facebook dan aplikasi sekolah), (2) guru mempersiapkan materi parenting class yaitu jadwal bulanan, pengumuman atau informasi dari pihak sekolah dan yayasan, dan info kegiatan di luar sekolah, atau di KB-TK Bethany School lazim disebut field study.

Proses selanjutnya yaitu pembahasan materi oleh guru masing-masing jenjang. Berdasarkan wawancara dengan para guru, dalam pembahasan ini masing-masing guru pengampu di tiap sentra akan menyampaikan kepada perwakilan guru yang akan masuk ke dalam pertemuan, hal-hal yang perlu disampaikan kepada orang tua siswa. Kemudian, jika ada tambahan pengumuman dari sekolah atau yayasan, maka Kepala Sekolah akan menyampaikan hal tersebut kepada guru sebelum pelaksanaan pertemuan. Yang terakhir yaitu, jika ada tambahan dari administrasi, tenaga kependidikan administrasi juga akan menyampaikan kepada guru. Dengan proses tersebut maka, orang tua mendapat hal-hal berikut; jadwal dan penjelasan materi pembelajaran dari guru (1), hal-hal yang perlu dipersiapkan orang tua siswa sehubungan dengan proses pembelajaran (2), pengumuman dari Kepala Sekolah, yayasan dan administrasi sekolah (3).

Dalam proses pelaksanaan orang tua hadir sesuai dengan jam pelaksanaan di masing-masing jenjang, dengan ruangan yang telah diinfokan sebelumnya dalam pengumuman. Dalam hal ini, berdasarkan observasi, hampir semua orang tua siswa yang hadir, datang tepat waktu bahkan sebelum jam pelaksanaan dimulai. Pelaksanaan program berlangsung selama 30 menit. Akan tetapi dalam observasi yang dilakukan, beberapa kali pelaksanaan, program berjalan lebih dari waktu yang telah diagihkan.

\section{Evaluasi tahap 4 penelitian discrepancy program parenting class di KB-TK Bethany School Salatiga.}

Pada tahap 4, yaitu produk, peneliti akan menganalisis tentang apakah tujuan dan proses pelaksanaan program parenting class sudah sejalan. Berdasarkan hasil wawancara dan melihat tahap 1 sampai 4, pada dasarnya seluruh pelaksanaan program parenting class di KBTK Bethany School sudah sesuai dengan standar atau desain program yaitu agar orang tua memahami dan dapat membantu persiapan pembelajaran anak di bulan yang akan datang telah tercapai. Hal tersebut terbukti dari hasil wawancara dengan orang tua siswa bahwa mereka dapat mengulang pelajaran yang disampaikan guru, dengan putra-putri mereka di rumah.

Orang tua siswa juga dapat mempersiapkan hal-hal yang diminta oleh guru demi kelancaran proses belajar putra-putri mereka di sekolah. Persiapan tersebut dapat berupa persiapan kelengkapan bahan ajar maupun persiapan untuk kegiatan belajar di luar sekolah. Perlu diketahui bahwa di KB-TK Bethany School, hampir setiap bulan diadakan pembelajaran di luar sekolah. Dengan kehadiran orang tua siswa pada parenting class maka info mengenai kegiatan di luar sekolahpun dapat tersampaikan dengan baik.

Pelaksanaan program parenting class dapat berjalan dengan lancar. Hampir seluruh orang tua siswa dapat hadir pada waktu yang telah ditentukan. Guru dapat melaksanakan penyampaian informasi dari sekolah dengan tepat sasaran.

Dari hasil penelitian, dalam tahap desain berfokus pada penentuan obyektif, proses, aktivitas, dan mendeskripsikan sumber yang dibutuhkan dan peserta untuk penerapan kebijakan untuk mencapai tujuan. Menurut Pedoman Penyelenggaraan Parenting yang disusun oleh (Direktorat Pembinaan Pendidikan Anak Usia Dini Direktorat Jenderal Pendidikan Anak Usia Dini, 2012), pelaksaan parenting bisa dilakukan dengan bentuk Kelas Pertemuan Orang tua, melibatkan orang tua di kelas, melibatkan orang tua di acara bersama, mengadakan hari konsultasi orang tua dan guru, berkunjung ke rumah siswa, membuat kegiatan sesuai dengan keperluan lembaga sekolah masing-masing. 
Bentuk program parenting di KB-TK Bethany School sudah sesuai dengan pedoman yaitu kelas pertemuan orang tua, acara bersama dengan orang tua, hari konsultasi dan kunjungan ke rumah siswa. Sementara itu, tugas lembaga menurut Pedoman Penyelenggaraan Parenting yang disusun oleh (Direktorat Pembinaan Pendidikan Anak Usia Dini Direktorat Jenderal Pendidikan Anak Usia Dini, 2012) yaitu: (1) Menyediakan tempat pelaksaan kegiatan, (2) Menyediakan sarana pelaksanaan kegiatan sesuai dengan situasi dan keperluan orang tua, (3) Menyediakan waktu dan akstivitas untuk dikerjakan bersama-sama dengan orang tua, (4) Menginformasikan kegiatan parenting kepada orang tua, (5) Memberi rekomendasi siapa narasumber yang cocok dengan kebutuhan orang tua.

KB-TK Bethany School sudah melaksanakan tugas sesuai pedoman yaitu menyediakan tempat untuk pelaksanaan program yaitu ruang kelas dan ruang pertemuan, penyediaan waktu dan aktivitas untuk dikerjakan bersama orang tua dilaksanakan dalam bentuk kegiatan dalam bentuk program, memberikan informasi. Sarana dan prasarana yang digunakan dalam kegiatan yaitu ruang kelas, LCD proyektor, Laptop, website dan aplikasi sekolah dan jadwal bulanan. Tujuan pelaksanaan program ialah penyatuan cara mengajar orang tua dan guru. Hal ini sejalan dengan penelitian (S., 2018) yang menyatakan: Program parenting berpengaruh positif terhadap perkembangan anak terutama pada orang tua yang iktu berpartisipasi dalam sinkronisasi. progam sekolah.

Peserta program ialah orang tua, anggota keluarga dan pengasuh. Hal ini sejalan dengan penelitian yang dilakukan oleh (Monikasari, 2013) yang menyatakan pelaksanaan program parenting ditujukan kepada orang tua peserta didik sebagai pesertanya. Terpenuhinya lebih dari $80 \%$ aspek desain program dari pedoman dan sekolah membuat desain program di KB-TK Bethany School dinilai baik.

Dalam tahap instalasi dianalisa apakah semua yang ada dalam desain sudah terlaksana. Terpenuhinya lebih dari delapan puluh persen aspek instalasi program dari pedoman dan sekolah membuat instalasi program di KB-TK Bethany School dinilai baik.

Tahap 3 terdapat 4 kesenjangan yang terjadi selama pelaksanaan program yaitu: (1) Belum terlaksananya keterlibatan orang tua di dalam kelas, (2) Terhentinya pemberian rekomendasi narasumber untuk kegiatan parents to parents. (3) Belum adanya gabungan berita dan bacaan pendamping orang tua (4) Peserta tidak hanya orang tua tetapi juga pengasuh yang bukan keluarga. Namun kesenjangan tersebut tidak membawa tahap proses ke penilaian yang buruk, akan tetapi penilaian tahap proses tetap melebihi lebih dari delapan puluh persen aspek proses program dari pedoman dan sekolah membuat proses pelaksanaan program di KB-TK Bethany School dinilai baik.

Tahap 4, tujuan parenting di KB-TK Bethany School yaitu mewadahi orang tua agar dapat memberikan cara mengajar yang sama dengan yang di sekolah telah tercapai. Hal ini sejalan dengan (Lindasari et al., 2017) yang menyatakan bahwa perlu adanya keterlibatan orang tua dalam lingkup sekolah, yaitu sebagai partner kerja atau sebagai pengajar di rumah, dengan menyediakan program parenting agar orang tua dapat melakukan tugasnya sebagai pengajar. Lebih lanjut (Syur'aini et al., 2018) dalam penelitiannya menyatakan bahwa perlu ada program dalam PAUD yang berkolaborasi dengan orang tua karena hamper seluruh kehidupan anak usia dini ada di keluarga. Maka tujuan program di KB-TK Bethany dinilai baik karena lebih dari delapan puluh persen tujuan tercapai.

Dalam tahap 5 Program parenting dibandingkan dengan program lain yaitu $\mathrm{A}$ to $\mathrm{Z}$ (program siaran radio anak), dan program drama anak-anak. Setiap program memiliki manfaat sendiri. Program A-Z bermanfaat untuk mengasah kemampuan komunikasi anak di depan umum dan program drama bermanfaat untuk mengasah kemampuan anak untuk berbahasa Inggris serta keberanian untuk tampil di depan penonton.

KB-TK Bethany School tidak mengeluarkan biaya khusus dalam penyelenggaraan program parenting. Namun, program ini tetap bermanfaat bagi sekolah dan orang tua murid secara khusus. Seperti yang dinyatakan tujuan program, manfaat yang didapat dari program ini, orang tua dapat mengajarkan materi di sekolah sama dengan di rumah. Selain 
itu kegiatan lain seperti kunjungan ke rumah siswa dan acara bersama orang tua dapat semakin mempererat hubungan antara orang tua dan guru. Hal tersebut bermanfaat bagi hubungan yang baik serta kerja sama antara sekolah dengan orang tua.

\section{SIMPULAN}

Simpulan yang dapat ditarik dari evaluasi program parenting class di KB-TK Bethany School yaitu: desain, instalasi, proses dan produk program sesuai dengan pedoman pelaksanaan program parenting. Ditemukan 4 kesenjangan dalam proses pelaksaan program namun tujuan program telah tercapai. Keseluruhan tahap 1-5 di program parenting KB-TK Bethany School bernilai baik yaitu lebih dari $80 \%$ aspek pedoman dari pemerintah. Diharapkan agar program parenting class yang telah berjalan, dapat dilanjutkan dengan penyempurnaan. Penelitian yang selanjutnya dapat dikembangkan dengan cara melakukan penelitian menyeluruh kegiatan parenting di KB-TK dan jenjang yang lebih tinggi.

\section{UCAPAN TERIMAKASIH}

Kami ucapkan terima kasih kepada seluruh pihak di KB-TK Bethany School, Kepala Sekolah, guru serta orang tua siswa yang telah mengijinkan penulis untuk melakukan wawancara dan pengambilan data penelitian ini.

\section{DAFTAR PUSTAKA}

Arikunto, S., \& Safrudin Abdul Jabar. (2009). Evaluasi Program Pendidikan. Bumi Aksara.

Arikunto, S., \& Safrudin Abdul Jabar. (2014). Evaluasi Program Pendidikan Pedoman Teoritis Bagi Mahasiwa dan Praktisi Pendidikan. Bumi Aksara.

Ayudia, C. (2014). Upaya Kepala Sekolah dalam Meningkatkan Partisipasi Orang tua di SDN Kecamatan Pariaman Utara Kota Pariaman. Bahana Manajemen Pendidikan, 2(1). http://103.216.87.80/index.php/bahana/article/view/3739/2974

Cutlip, S. M., Center, A. H., \& Broom, G. M. (2011). Effective Public Relations (9th ed.). Kencana.

Direktorat Pembinaan Pendidikan Anak Usia Dini Direktorat Jenderal Pendidikan Anak Usia Dini, N. dan I. K. P. N. (2012). Pedoman Penyelenggaraan Pendidikan Anak Usia Dini Berbasis Keluarga. https://drive.google.com/file/d/0B1xIqIGe4j8MFE4Z1pWN1QtWTQ/view. https://doi.org/10.24832/jpkp.v1i1.177.

Fitroh, S. F., \& Oktavianingsih, E. (2020). Peran Parenting dalam Meningkatkan Literasi Kesehatan Ibu terhadap Stunting di Bangkalan Madura. Jurnal Obsesi : Jurnal Pendidikan Anak Usia Dini, 4(2), 610-619. https:/ / doi.org/10.31004/ obsesi.v4i2.415

Ftizpatrick, J. L., Sanders, J. R., \& Worthen, B. R. (2004). Program Evaluation: Alternative Approaches and Practical Guidelines. Pearson.

Lenny Nuraeni, Andrisyah, R. N. (2019). Efektivitas Program Sekolah Ramah Anak dalam Meningkatkan Karakter Anak Usia Dini. Jurnal Obsesi : Jurnal Pendidikan Anak Usia Dini, 4(1), 20-29. https:// doi.org/10.31004/obsesi.v4i1.204

Lindasari, E., Wiyono, B. B., \& Arifn, I. (2017). MANAJEMEN PARENTING DALAM MENINGKATKAN HUBUNGAN SEKOLAH DENGAN ORANGTUA. Manajemen Dan Supervisi Pendidikan, 1(2), 146-155. http://ap.fip.um.ac.id/wpcontent/uploads/2015/04/emi-linda.pdf. https://doi.org/10.17977/um025v1i22017p146.

Monikasari, Ci. (2013). Pelaksanaan Program Parenting Bagi Orang tua Peserta Didik di PAUD Permata Hati. Diklus, Jurnal Pendidikan Luar Sekolah, 17(1). https://journal.uny.ac.id/index.php/diklus/article/view/2896/2444

Nelliraharti Nelliraharti, \& Sari, Y. (2019). PELAKSANAAN PRORAM PARENTING BAGI ORANG TUA SISWA DI KUTTAB AL-FATIH BANDA ACEH. Journal of Education Science, 5(2). http://jurnal.uui.ac.id/index.php/jes/article/view/493 
Nooraeni, R. (2017). Implementasi Program Parenting Dalam Menumbuhkan Perilaku Pengasuhan Positif Orang Tua Di PAUD Tulip Tarogong Kaler Garut. Jurnal Pendidikan Luar Sekolah, 13(2). https:// ejournal.upi.edu/index.php/pls/article/view/8750/5430

Permatasari, E., Handayani, T., \& Hamzah, A. (2019). Kerjasama Orang tua dan Guru di MI Hijriyah IV Palembang dalam Upaya Pencegahan Penyalahgunaan Smartphone. Primary Education Journal. http://pej.ftk.uinjambi.ac.id/index.php/PEJ/index

Pidarta, M. (2011). Manajemen Pendidikan Indonesia. Rineka Cipta.

Putri, A. E. (2019). Evaluasi Program Bimbingan dan Konseling: Sebuah Studi Pustaka. Jurnal Bimbingan Konseling Indonesia, 4(2), 39-42. https://journal.stkipsingkawang.ac.id/index.php/JBKI/article/view/890/pdf. https:// doi.org/10.26737/jbki.v4i2.890.

Rahayu, S. (2018). Pentingnya Program Parenting dalam Pendidikan Anak Usia Dini. http://anggunpaud.kemdikbud.go.id/index.php/berita/index/20180927155114/Pe ntingnya-Program-Parenting-dalam-Pendidikan-Anak-Usia-Dini

Rahman, H. A., Affandi, H. M., Effendi, M., \& Matore, E. M. (2018). Evaluating School Support Plan: A Proposed Conceptual Framework Using Discrepancy Evaluation Model. International Journal of Education, Psychology and Counseling, 3(17), 49-56. http://www.ijepc.com/PDF/IJEPC-2018-17-09-05.pdf

S., S. (2018). Pengaruh Program Parenting terhadap Perkembangan Kemandirian Anak Usia Dini. Palita: Journal of Social Religion Research, 2(2), 161-174. http:/ / ejournal.iainpalopo.ac.id/index.php/palita/article/view/124

Siregar, F. A. (2018). Mengelola Hubungan Sekolah dan Masyarakat. IJTIMAIYAH JURNAL $\begin{array}{lllll}\text { PENDIDIKAN ILMU SOSIAL DAN } & \text { BUDAYA, }\end{array}$ http://jurnal.uinsu.ac.id/index.php/ijtimaiyah/article/view/4475

Siti Chumaerotin, Munawar, M., \& Karmila, M. (2019). Pentingnya Program Parenting Pada Era Globalisasi di Lembaga Paud. Seminar Nasional Paud 2019. http://conference.upgris.ac.id/index.php/Snpaud2019/article/view/434

Sudjana, N. (2017). Dasar-Dasar Proses Belajar. Sinar Baru Algesindo.

Syur'aini, Setiawati, \& Sunarti, V. (2018). Penyusunan Program Parenting Bagi Pengelola Dan Pendidik Paud Di Nagari Lubuk Jantan Kecamatan Lintau Buo Utara. Kolokium, Jurnal Pendidikan Luar Sekolah, http://kolokium.ppj.unp.ac.id/index.php/kolokium-pls/article/view/13/pdf

Ulva, C. H. (2017). No Title. Universitas ISlam Negeri AR-Raniry Banda Aceh. https:// doi.org/10.24036/kolokium-pls.v6i2.13

Yusup, W. B., Ismanto, B., \& Wasitohadi. (2019). Evaluasi Program Indonesia Pintar dalam Peningkatan Akses Pendidikan di Sekolah Menengah Pertama. Kelola, Jurnal Manajemen Pendidikan, 6(1), 45-53. https:/ / ejournal.uksw.edu/kelola/article/view/1498/1196. https:// doi.org/10.24246/j.jk.2019.v6.i1.p44-53. 